\title{
Diagnosing childhood Tuberculosis in rural clinics in Mpumalanga Province, South Africa
}

\author{
SC Vellema, MA Public Health \\ Communicable Disease Control Manager, Gert Sibande District, Mpumalanga Department of Health, South Africa \\ DN Durrheim, DrPH, MPH\&TM, MBChB, FAFPHM \\ Service Director, Health Protection, Hunter New England Population Health and Conjoint Professor of Public \\ Health, University of Newcastle, New South Wales, Australia
}

JE Smith, MA Cur, Lecturer, Department of Health Studies, UNISA, Pretoria, South Africa

Key words: tuberculosis, children, diagnosis, Mpumalanga, nurse, primary health care, score chart.

\section{Correspondence address:}

Professor David N Durrheim

Locked Bag 10, Wallsend,

New South Wales, 2287

Australia

Fax: 09-61-2-49246048

Email:

David.Durrheim@hnehealth.nsw.gov.au

\section{Abstract: Curationis 31(1): $52-58$}

Background: Tuberculosis is a major global public health challenge and disease in young children is particularly severe. Diagnosing tuberculosis in children is complex as clinical presentation is often atypical and available diagnostic modalities are imperfect. Diagnosis is particularly challenging in developing countries where resources and access to sophisticated facilities are limited. The South African primary health care system requires frontline nurses to be equipped to suspect, diagnose and treat children with tuberculosis, but their capacity to diagnose childhood tuberculosis is unknown. Relatively low rates of childhood tuberculosis notification suggested that tuberculosis may have been under-diagnosed in Mpumalanga Province.

Objective: To determine the ability of the primary health care nurses to diagnose childhood tuberculosis in primary care public health facilities in Gert Sibande District, Mpumalanga Province.

Methodology: Within-method triangulation by means of a self-completed questionnaire and a facility audit of records and diagnostic aids, was used to assess nurses' knowledge and determine whether primary health care facilities were adequately equipped to facilitate the diagnosis of childhood tuberculosis.

Results: There was a limited appreciation of the need to use complementary clinical and epidemiological features and diagnostic approaches to diagnose childhood tuberculosis. Child contacts had only been screened in $22.6 \%$ (111/491) of confirmed smear positive adult tuberculosis cases reviewed. The diagnostic score chart advocated by the World Health Organization and South African Department of Health was only used by $16 \%(10 / 62)$ of the facilities. Nurses who had been specifically trained on tuberculosis were more knowledgeable about diagnostic approaches and all respondents who were using the score chart had received specific tuberculosis training. Conclusion: The deficiencies in knowledge and practice evident during this survey and practice audit could at least partially explain the relatively low detection rates of childhood tuberculosis in Gert Sibande district, Mpumalanga Province. There is a need to equip primary health care nurses with the knowledge, support and access to diagnostic tests required to ensure a high index of suspicion and early, effective, diagnosis of tuberculosis in children. 
Table 1 Children as a proportion of the total population and of all TB patients diagnosed in Mpumalanga, South Africa, 2001-2003

\begin{tabular}{|c|c|c|c|c|c|c|c|}
\hline Year & $\begin{array}{l}\text { Total TB } \\
\text { patients }\end{array}$ & $\begin{array}{c}\text { TB Patients } \\
<5 \text { Years of } \\
\text { age }\end{array}$ & $\begin{array}{c}\% \text { of } \mathrm{TB} \\
\text { patients }<5 \\
\text { years of age }\end{array}$ & $\begin{array}{c}\text { \%of total } \\
\text { population }<5 \\
\text { years of age }\end{array}$ & $\begin{array}{c}\text { TB patients } \\
5-<15 \text { years } \\
\text { of age }\end{array}$ & $\begin{array}{c}\% \text { of TB } \\
\text { patients 5- } \\
<15 \text { years of } \\
\quad \text { age }\end{array}$ & $\begin{array}{c}\text { \% of total } \\
\text { population } \\
5-<15 \text { years } \\
\text { of age }\end{array}$ \\
\hline 2001 & 7175 & 345 & 4,8 & 11,2 & 208 & 2,8 & 23,9 \\
\hline 2002 & 8047 & 355 & 4,4 & 11,1 & 252 & 3.1 & 23,7 \\
\hline 2003 & 7732 & 359 & 4,6 & 10,9 & 262 & 3,3 & 23,6 \\
\hline
\end{tabular}

Department of Health (2004:1-4)

Table 2 Children as a proportion of the total population and of all TB patients diagnosed in Gert Sibande district, Mpumalanga, 2001-2003

\begin{tabular}{|c|c|c|c|c|c|c|c|}
\hline Year & $\begin{array}{l}\text { Total TB } \\
\text { patients }\end{array}$ & $\begin{array}{c}\text { TB Patients } \\
<5 \text { Years of } \\
\text { age }\end{array}$ & $\begin{array}{c}\% \text { of TB } \\
\text { patients }<5 \\
\text { years of age }\end{array}$ & $\begin{array}{c}\text { \%of total } \\
\text { population }<5 \\
\text { years of age }\end{array}$ & $\begin{array}{c}\text { TB patients } \\
5-<15 \text { years } \\
\text { of age }\end{array}$ & $\begin{array}{c}\% \text { of } \mathrm{TB} \\
\text { patients } 5- \\
<15 \text { years of } \\
\quad \text { age }\end{array}$ & $\begin{array}{c}\% \text { of total } \\
\text { population } \\
5-<15 \text { years } \\
\text { of age }\end{array}$ \\
\hline 2001 & 2162 & 79 & 3,6 & 5,6 & 19 & 0,8 & 12,0 \\
\hline 2002 & 2665 & 71 & 26 & 5,6 & 72 & 2,7 & 12,0 \\
\hline 2003 & 3078 & 125 & 4,0 & 5,6 & 90 & 29 & 12,0 \\
\hline
\end{tabular}

Department of Health (2004:1-4)

\section{Introduction}

Tuberculosis (TB) has re-emerged as a global public health priority in the past three decades and South Africa is one of ten countries contributing most to the global burden of new cases. As the recommended strategy for TB control, Directly Observed Treatment, shortcourse (DOTS), had traditionally focused on detecting and curing smear positive patients. Children diagnosed with pulmonary $\mathrm{TB}$ are rarely sputum smear positive so they have not been considered an important component of the global control strategy (Enarson, 2004:143).

However, the importance of childhood TB has recently been acknowledged. Not only does childhood TB represent a sentinel event in the community suggesting recent transmission from an infectious adult (Shingadia and Novelli,
2003:624), but rapid progression of TB is more common and more frequently fatal in young children if not promptly diagnosed and treated (Cremin and Jamieson, 1005:67). Children have been recognized as an important part of the infectious pool contributing to ongoing transmission (Lienhardt, Sillah, Fielding, Bennett, Donkor, Warndorff, McAdam and Manneh, 2003:608; Zar, Hanslo, Apolles, Swingler and Hussey, 2005:130).

Unfortunately diagnosing TB in childhood is challenging with as few as $40 \%$ of clinically suspected cases confirmed (Schaaf, Beyers, Gie, Nel, Smuts, Scott, Donald and Fourie, 1995:189). Many of the symptoms and signs of childhood TB are non-specific (Beyers, Gie, Schaaf, Van Zyl, Nel, Talent and Donald, 1994:261). A number of common chronic childhood illnesses in sub-Saharan Africa, including HIV and malnutrition, mimic TB and frequently coexist in the same patient, resulting in tremendous diagnostic and therapeutic challenges for health workers (Van Rheenen, 2002:435). The lack of a definitive diagnostic tool for paediatric TB is a limiting factor in diagnosis (Chintu, Bhat, Luo, Raviglione, Diwan, Du Pont and Zumla, 1993:502). Currently it is essential to consider the constellation of physical signs (Gie, Beyers, Schaaf, Nel, Smuts, Van Zyl and Donald, 1995:659) in concert with the findings from diagnostic tools, including chest $\mathrm{x}$-rays, tuberculin testing and other special investigations and a history of a close contact with an adult case of pulmonary TB to make a diagnosis of TB in a child (Schaaf, Beyers, Gie, Nel, Smuts, Scott, Donald and Fourie, 1995:192). Scoring systems and algorithms have been developed to facilitate the diagnosis of childhood TB (Balt, Edgington, Lotter, 
Preller and Uys, 1998:88).

\section{Problem statement}

The National TB Directorate alerted the Mpumalanga Communicable Diseases Control Directorate in December 2002 that TB case finding amongst Mpumalanga children was much lower than expected. Epidemiological review of notified TB cases and population demographics confirmed this concern (Table 1). Of the five South African provinces that had implemented the electronic TB register in 2002, Mpumalanga had the lowest proportion of TB cases amongst children $<15$ years of age, and this was again found in 2003 among the six provinces using the electronic register. The proportion of pulmonary TB diagnosed in children was particularly low in Gert Sibande district, one of the three health districts in Mpumalanga province (Table 2).

The ability of primary health care (PHC) nurses based in $\mathrm{PHC}$ facilities to diagnose TB in children was considered a possible contributory factor to low notification rates. $\mathrm{PHC}$ nurses are usually the initial contact for sick children within the formal health sector in South Africa and many other developing countries (WHO, 2003:3). Diagnosis of TB will not occur unless PHC nurses are alert to the possibility of TB and apply an appropriate approach to diagnosis (Baez, 2000:10).

\section{Study aim and objectives}

The study aimed to explore specific factors that could affect the ability of PHC nurses to diagnose TB in children in the Gert Sibande district, Mpumalanga Province by:

- $\quad$ Determining the knowledge and skills of nurses regarding TB diagnosis in children;

- Establishing whether the PHC setting was adequately equipped to diagnose TB in children;

- $\quad$ Evaluating the completeness of screening of children who were contacts of confirmed smear positive adult TB cases.

\section{Literature review}

The ability of South African PHC nurses to diagnose $\mathrm{TB}$ in children has not previously been studied (Baez, 2000:1). An essential factor in diagnosing TB in children is a high degree of suspicion (Gie et al, 1995). Symptoms of respiratory TB in children are often non-specific and include coughing and wheezing (Beyers, Gie, Schaaf, Van Zyl, Nel, Talent and Donald, 1994:264), which may be misdiagnosed as pneumonia, bronchopneumonia or asthma (Gie et al, 1995).

Diagnosis of TB in children relies heavily on correct administration and interpretation of tuberculin skin tests (Department of Health, 2000:32). Beyers et al (1994) recommended greater utilization of skin testing to shorten the delay between diagnosis and onset of treatment. A negative tuberculin test does not exclude TB and many conditions suppress the tuberculin test (Harries, Maher, Raviglione, Chaulet, Nunn, Van Praag and Crofton, 1996:66). Tuberculin skin testing is less useful in HIV infected children because of HIV-related cutaneous anergy (Van Rheenen, 2002:440) and may be falsely negative in the presence of malnutrition (Van Beekhuizen, 1998:155). Infection with environmental mycobacteria and prior vaccination with Bacillus CalmetteGuerin (BCG) vaccine may interfere with tuberculin reactions because of the induction of tuberculin reactivity (Arnadottir, Rieder, Trebucq and Waaler, 1996:1).

Chest radiography remains the means by which childhood TB is most frequently confirmed, but its merit continues to be debated (Schaaf et al, 1995). Donald, Fourie and Grange (1999:154) stated that "interpretation of a chest radiograph in a young child is fraught with difficulty because of exposure of the film in expiration, excessive lordosis, rotation of the thorax and faulty exposure of processing."

Although sputum smear microscopy is not the "gold" standard test in children that it is in adults (Harries et al, 1996), sputum induction in infants and young children can be done safely and effectively, and should be attempted for bacteriologic confirmation of pulmonary TB in children (Zar, Tannenbaum, Appoles, Roux, Hanlo and Hussey, 2000:1151).

The "Road to Health" card is another tool that can be used by PHC nurses to assist in the diagnosis of childhood TB (Donald, Schoeman and Van Schalkwyk, 1985:117). All children who fail to gain or lose weight should be evaluated for TB (Donald, Fourie and Grange, 1999:160; Pearson, 1992:35).

Score charts to assist in diagnosis are recommended by the WHO. Children may miss out on curative TB therapy when a score chart is not adequately utilized (Osborne, 1995:371). Crofton, Horne and Miller (1992:49) advised complementing the score chart with a paediatric tuberculosis flow chart or algorithm once a child has a history of respiratory symptoms of longer than two weeks duration. Kibel and Wagstaff (1995:289) and Schaaf et al (1995) endorsed the graduated WHO approach to diagnosis in South Africa that results in children being classified as having suspect, probable or confirmed respiratory $\mathrm{TB}$.

Contact tracing can contribute to TB control in developing countries but is rarely performed, because of resource constraints (Lienhardt, Sillah, Fielding, Bennett, Donkor, Warndorff, McAdam and Manneh, 2003:608). A history of a close contact with an adult diagnosed with pulmonary TB provides strong support for the diagnosis of TB in a child (Schaaf, Donald and Scott, 1991:223).

\section{Methodology}

All 62 provincial government public health facilities in the Gert Sibande district were included in the study. This included 36 permanent clinics, 17 mobile clinics and 9 community health care centers.

Three complementary research approaches were used:

A self-administered questionnaire was completed by the PHC health worker primarily responsible for TB management in each facility. The questionnaire collected information on the health facility, respondent's previous TB management training and perceived need for training, current involvement in management of paediatric $T B$, and explored their knowledge relating to $\mathrm{TB}$ diagnosis in children.

A site visit was conducted at each facility to assess whether PHC nurses were equipped to diagnose TB in children. This structured review was conducted by the Principal Investigator (SCV) using a checklist with yes or no options for each item.

During the clinic visit, a record review 
was also conducted, with the last ten records or as many as were available on the facility's electronic register reviewed to assess current practice. A total of 491 records were reviewed (five facilities had not yet adopted the system, five facilities had not registered any new TB patients in the past year and five facilities had fewer than 10 records). The official hardcopy TB records, GW20/12, were also examined to assess completeness of patient contact follow up.

The study methods and tools were pretested at seven local government facilities in the district for face and content validity, and this resulted in some minor adaptations.

Data were electronically captured in an Excel for Windows spreadsheet and analysed using the Statistical Analysis System (SAS) for Windows version 9.1. Selvanathan, Selvanathan, Keller, Brian and Bartel's (1994) statistical technique (in O'Leary \& Cotter, 2000:111) was applied to compare proportions between groups.

The respondents provided informed consent prior to participation and were guaranteed that only collated data would be made available in printed reports. The University of South Africa's Research Ethics Committee and the Mpumalanga Government Health Research Committee approved the proposal.

\section{Results}

\section{Demographics of respondents}

A PHC nurse was the respondent at 59 facilities, while two enrolled nurses and a community volunteer DOTS supporter were primarily responsible for TB management in children at the remaining three facilities and participated in the survey. Fifty-one respondents were female and the median age of respondents was 39 years (range 24 to 61 years). Of the 59 registered nurses, $80,6 \%(\mathrm{~N}=50)$ had additional qualifications in midwifery. Most respondents, $85,4 \%$ ( $\mathrm{N}=53$ ), were situated in rural areas. Just more than half of the respondents, $53,2 \%$ $(\mathrm{N}=33)$, had received TB training since qualifying, of which $57,5 \%(\mathrm{~N}=19)$ had completed a three-day specialized TB training course offered in Mpumalanga Province. In the preceding five years, $45,5 \%(\mathrm{~N}=27)$ of all health workers surveyed $(\mathrm{N}=62)$ had been trained. All respondents except one nurse who had received 10 days of training indicated that they would benefit from additional training on TB.

\section{General TB knowledge}

Although $77,4 \% \quad(\mathrm{~N}=48)$ of the respondents knew that sputum positive adults were the main focus of TB control, only $38,7 \%(\mathrm{~N}=24)$ correctly indicated that children under 2 years of age were the age-group at greatest risk of developing serious forms of $\mathrm{TB}$.

Most respondents identified that overcrowded living conditions $87,1 \%$ $(\mathrm{N}=54)$, poor ventilation $67,7 \%(\mathrm{~N}=42)$, malnutrition $79,0 \%(\mathrm{~N}=49)$ and poverty $77,4 \%(\mathrm{~N}=48)$, were factors associated with an increased risk of TB in children. However, only $27,4 \%$ ( $\mathrm{N}=17$ ) identified exposure to cigarette smoke and $8,0 \%$ $(\mathrm{N}=5)$ smoke derived from household wood and coal fires as risk factors.

\section{Childhood TB diagnosis}

Only $19,3 \%(\mathrm{~N}=12)$ of the respondents indicated that persistent wheezing and $41,9 \%(\mathrm{~N}=26)$ that fever were suggestive symptoms of TB in children, in addition to cough and weight loss.

The majority of the respondents, namely $83,8 \%(N=52)$ knew that a tuberculin test should be performed when TB was suspected and $64,5 \%(\mathrm{~N}=40)$ knew that a positive tuberculin test meant that a child was infected with TB. The knowledge of respondents about conditions that could suppress a tuberculin test was limited, with $48,3 \%(\mathrm{~N}=30)$ indicating HIV, 20,9\% ( $\mathrm{N}=13)$ malnutrition, $16,1 \%(\mathrm{~N}=10)$ corticosteroids, $8,0 \%(\mathrm{~N}=5)$ cancer treatment and 22,5\% (N=14) disseminated TB. Only $56,4 \%(\mathrm{~N}=35)$ correctly indicated that the diameter of the swelling rather than its height indicated previous TB infection.

The TB Score Chart (TSC), currently advocated as best practice for diagnosing TB in children in developing countries, was not widely used. Although $25,8 \%$ $(\mathrm{N}=16)$ of respondents indicated that they had used the scoring system in the self-administered questionnaire, during the clinic audit visit only $16,1 \%(\mathrm{~N}=10)$ indicated that they actually used it and all of these staff had received specialized TB training.

More respondents who had received TB training knew how to interpret a positive tuberculin test $(74,5 \%$ compared to
$51,0 \%$ who did not receive TB training) and the correct site for administering a tuberculin test $(84,8 \%$ compared to $51,7 \%$ who did not receive TB training). They also more frequently valued tuberculin tests $(69,6 \%$ compared to $58,6 \%$ who did not receive TB training), chest $\mathrm{X}$-rays (51,5\% compared to $31,0 \%$ who did not receive $\mathrm{TB}$ training) and history of contact with a person with sputum positive pulmonary TB $(84,8 \%$ compared to $51,7 \%$ who did not receive TB training) for diagnosing TB in children.

\section{Clinic visits - audit check list and record review for patient contacts}

At each facility; the researcher verified how many of the last 10 admissions had the contact section of their hard-copy official TB record completed (GW20/12). Four hundred and ninety one records were reviewed and only $2,3 \%(\mathrm{~N}=11)$ had the section on child contacts completed. Reasons provided for not completing the contact session were forgetfulness, time constraints and no appreciation of why it was important.

Contact tracing was mostly performed by volunteers $53,2 \% \quad(\mathrm{~N}=33)$, with professional nurses $14,5 \%(\mathrm{~N}=9)$, other categories of nurses $1,6 \%(\mathrm{~N}=1)$, health promotion practitioners $4,8 \%(\mathrm{~N}=3)$ and traditional healers $4,8 \%(\mathrm{~N}=3)$ also involved. At $10(16,1 \%)$ clinics no contact tracing was conducted.

The majority of facilities, 91,9\% ( $\mathrm{N}=57$ ), indicated that they had prophylactic INH and rifampicin syrup in stock for children.

One professional nurse indicated that she had initiated trials of TB treatment in children with suspicious clinical signs, considering clinical improvement as diagnostic of TB. Of equal concern was that $6,4 \%(\mathrm{~N}=4)$ of sites indicated that children were referred to their clinics by general practitioners to receive TB medication as a diagnostic trial.

The facility audit revealed a number of important deficiencies in TB management and uncovered constraints to confirming TB diagnosis in children (Table 3)

Most clinics had guidelines, sputum bottles, TB medicines and prophylactic medicine for children in stock (Table 3). There was no ability to perform X-Rays or gastric washings at any facility and TB score systems and Tuberculin tests 


\begin{tabular}{|c|c|}
\hline Question & Yes \\
\hline Did the clinic have a fast lane for TB DOT patients? & $22,6 \%(\mathrm{~N}=14)$ \\
\hline Did the clinic have a fast lane for coughing patients? & $51,6 \%(\mathrm{~N}=32)$ \\
\hline $\begin{array}{l}\text { Did the clinic have a copy of the South African TB Control Programme, Practical Guidelines } \\
(2000) \text { ? }\end{array}$ & $88,7 \%(\mathrm{~N}=55)$ \\
\hline Did they have a copy of Tuberculosis - A Training Manual for Health Workers (1998)? & $88,7 \%(\mathrm{~N}=55)$ \\
\hline Did the clinic use any TB score system for assisting with the diagnosis of TB in children? & $16,1 \%(\mathrm{~N}=10)$ \\
\hline Did the clinic use any algorithm to help them manage child contacts of infectious adults? & None \\
\hline Did the clinic use the suggested diagnostic pathways for children withsuspected TB? & None \\
\hline $\begin{array}{l}\text { Did the clinic use the WHO guidelines for classifying children as havingsuspected, } \\
\text { probable- or confirmed TB? }\end{array}$ & None \\
\hline Did the clinic have a cough register? & $77,4 \%(\mathrm{~N}=48)$ \\
\hline Were sputum bottles available? & $93,5 \%(\mathrm{~N}=58)$ \\
\hline Were there any stock outs of sputum bottles in the past 6 months? & $6,4 \%(\mathrm{~N}=4)$ \\
\hline Did the clinic have any Tuberculin tests in stock? & $46,7 \%(\mathrm{~N}=29)$ \\
\hline Did the clinic have any Tuberculin stock-outs during the past 6 months? & $6,4 \%(\mathrm{~N}=4)$ \\
\hline Did the clinic have X-Ray facilities available on site? & None \\
\hline Did the clinic have all the TB medicines for treating PTB in children in stock? & $91,4 \%(\mathrm{~N}=57)$ \\
\hline Did the clinic have any TB medicine stock-outs during the past 6 months? & $8,0 \%(\mathrm{~N}=5)$ \\
\hline Did they have any TB prophylactic medicines for children in stock? & $91,9 \%(\mathrm{~N}=57)$ \\
\hline Did the clinic have any stock-outs of TB prophylactic medicine during the past 6 months? & $6,4 \%(\mathrm{~N}=4)$ \\
\hline Did the clinic perform gastric washings on children for TB diagnosis? & None \\
\hline Did the clinic have the equipment necessary to perform gastric washing? & None \\
\hline
\end{tabular}

were the more commonly absent.

\section{Discussion}

Deficiencies in knowledge and practice found during the study would negatively impact on the likelihood of early suspicion and confirmation of pulmonary TB in Mpumalanga children. It is clear that nursing education needs to emphasise the increased risk of TB in children (Donald et al, 1999) to ensure a high index of suspicion amongst PHC nurses. Beyers et al (1994:624) have stated that the symptoms of childhood TB are relatively non-specific, with only a persistent cough and wheezing usually prominent. The two South African guidelines also list wheezing as a suggestive symptom. According to Crofton, Horne and Miller (1999:93), a wheeze due to lymph node pressure bronchi is gentle and heard both when inhaling and exhaling. It was thus disappointing that the importance of wheeze as a suggestive symptom was not widely appreciated.
Certain practices discovered could prove harmful to individual patients but also to the control programme. Trials of treatment as a diagnostic method have been outlawed as they often result in inadequate therapy and may fuel the selection of resistance. Unless a tuberculin test is correctly read, children will be misdiagnosed and delayed diagnosis could have a fatal outcome (Cremin and Jamieson, 1995:107).

There were potential missed 
opportunities for early diagnosis and prevention of $\mathrm{TB}$ amongst the child contacts of adult cases. It is well recognized that the prevention of TB in early infancy relies on the early detection and treatment of TB in the infant's mother or other members of the infant's household (Schaaf et al, 1995). A history of a close contact with an infectious adult and the occurrence of repeated or persistent respiratory infections in children in an area of high TB incidence should alert health care workers to the possibility of TB (Gie et al, 1995). Identification and tracing of child contacts of smear positive adults needs to be resolved at each facility.

Van Beekhuizen (1998:159) found that the TSC is a very helpful method for diagnosing TB in children at PHC facilities in developing countries, with only $5,0 \%$ of patients not correctly diagnosed by this method. The TSC is cost-effective and has been successfully implemented at PHC level in a number of developing countries. There is clearly scope for increasing its adoption in rural South African settings.

Training appeared to have had a positive impact on the PHC nurses' knowledge. However, a number of gaps in the content of the current training course became apparent. This study provides valuable information for further refining the local TB training course and for encouraging each facility to support nurse participation in TB training.

The study was conducted exclusively in the Gert Sibande district in Mpumalanga province, thus the findings should not be automatically generalized to other areas. However, it is likely that similar issues are prevalent in other South African provinces. The various datacollection methods complemented each other to provide a more complete picture of diagnostic practices by triangulation.

\section{Conclusions}

This multifaceted study found important deficiencies in PHC respondents' knowledge relating to diagnosing $\mathrm{TB}$ in children and detected limited screening of TB child contacts of confirmed smear positive adults. The study has resulted in a provincial plan of action that focuses on diagnosing and managing TB in children and includes universal implementation of the TB score chart, uniform contact tracing, and standardized equipment and consumables available in all PHC facilities. It is hoped that these improvements will ensure more complete detection and notification of $\mathrm{TB}$ in children, with earlier diagnosis and treatment resulting in decreased transmission and prevention of unnecessary morbidity and mortality.

\section{References}

ARNADOTTIR, T; RIEDER, HL; TREBUCQ, A \& WAALER, HT 1996:

Guidelines for conducting tuberculin skin test surveys in high prevalence countries. Tubercle and Lung Disease 77:1-19.

BAEZ, C 2000: TB in children. Update 56: $10-11$.

BAEZ, C 2003: TB in children: the missing diagnosis. Paper delivered at a Tuberculosis Congress at the University of the Free State, Bloemfontein on 11-12 November, 2003.

BALT,E; EIXINGTON.M: LOTTER.J PRELLER, A \& UYS. M 1998: Tuberculosis: a training manual for health workers. Pretoria: Van Schaik.

BEYERS N, GIE RP,SCHAAF HS, VAN ZYL S, NEL ED, TALENT JM \& DONALD PR. 1994: Delay in the diagnosis, notification and initiation of treatment compliance in children with diagnosis. Tubercle and Lung Diseases 75:260-265.

CHINTU, C; BHAT, G; LUO, C; RAVIGLIONE,M; DIWAN, V; DUPONT, HL \& ZUMLA, A 1993: Seroprevalence of human immunodefiency virus type 1 infection in Zambian children with tuberculosis. Pediatric Infectious Disease Journal 12:499-504.

CROFTON, J; HORNE, N \& MILLER, F 1992: Clinical tuberculosis. Kuala Lumpur: MacMillan.

CREMIN, BJ \& JAMIESON, DH 1995: Childhood tuberculosis: modem imaging and clinical concepts. London: SpringerVerlag.

DEPARTMENT OF HEALTH. 2000: The South African tuberculosis control programme practical guidelines. Pretoria: Government Printer.

DONALD,PR; SCHOEMAN,JF \& VAN SCHALKWYK, HJS 1985: The "Road to Health" card in tuberculosis meningitis.
Journal of Tropical Pediatrics 31:117120.

DONALD, PR; FOURIE, PB \& GRANGE, JM 1999: Tuberculosis in childhood. Pretoria: Van Schaik.

ENARSON, DA 2004: Children and the global tuberculosis situation. Paediatric Respiratory Review 5A:143-145.

GIE, RP; BEYERS, N; SCHAAF, HS; NEL, ED; SMUTS, NA; VAN ZYL, S \& DONALD, PR 1995: TB or not TB? South African Medical Journal 85:658-659.

HARRIES, AD; MAHER, D; RAVIGLIONE, MC; CHAULET, P; NUNN, PP; VAN PRAAG, EP \& CROFTON, J 1996: TB/HIV a clinical manual. Rome: Stabilimento Tipograficao Ferrero s.r.l. Romano Canaveso (TO).

KHAN, EA \& STARKE, JR 1995: Diagnosis of tuberculosis in children: increased need for better methods. Emerging Infectious Diseases 1:2

KIBEL, MA \& WAGSTAFF, LA 1995. Child health for all. Cape Town: Oxford University Press.

LIENHARDT,C; SILLAH,J;FIELDING, K; BENNETT, S; DONKOR, S; WARNDORFF, D; MC ADAM, K \& MANNEH, $K$ 2003: Risk factors for tuberculosis infection in children in contact with infectious tuberculosis cases in the Gambia, West Africa. Pediatrics 111:608-615.

OSBORNE, CM 1995: The challenges of diagnosing childhood tuberculosis in a developing country. Archives of Diseases in Childhood 72:369-371.

PEARSON, CA 1992: Tuberculosis in malnourished children. Tropical Doctor 22:35.

SCHAAF, HS; BEYERS, N; GIE, RP; NEL, ED; SMUTS, NA; SCOTT, FE; DONALD, PR \& FOURIE, PD 1995: Respiratory tuberculosis in childhood: the diagnostic value of clinical features and special investigations. Pediatric Infectious Diseases Journal 11:189-194.

SCHAAF, HS; DONALD,PR \& SCOTT, F 1991: Maternal chest radiography as supporting evidence for the diagnosis of tuberculosis in childhood. Journal of Tropical Pediatrics 37:223-225. 
1994: Australian business statistics. Australia: Thomas Nelson.

SHINGADIA, D \& NOVELLI, V 2003:

Diagnosis and treatment of tuberculosis in children. Lancet Infectious Diseases 3:624-632

VAN BEEKHUIZEN, H 1998: Tuberculosis score chart in children in Aitape, Papua New Guinea. Tropical Doctor 28:155-160.

VAN RHEENEN, P 2002: The use of the paediatric tuberculosis score chart in an HIV-endemic area. Tropical Medicine and International Health 7:435-441.

WORLD HEALTH ORGANIZATION. 2003. Fact sheet 13: How to find and cure TB. Geneva: WHO.

ZAR, HJ; TANNENBAUM, E; APOLLES, P; ROUX, P; HANSLO, D \& HUSSEY, G 2000: The microbiological diagnosis of pulmonary tuberculosis in infants and young children: sputum induction compared to gastric lavage. South African Medical Journal 90:1151.

ZAR, HJ; HANSLO, D; APOLLES, P; SWINGLER, G \& HUSSEY, G 2005:

Induced sputum versus gastric lavage for microbiological confirmation of pulmonary tuberculosis in infants and young children: a prospective study. Lancet 365:130. 